\title{
RELATIONSHIP PERCEPTIONS OF OCCUPATIONAL SAFETY AND HEALTH IMPLEMENTATION WITH EMPLOYEE'S WORK ATTITUDE PT. BETON PERKASA WICAKSANA JAKARTA, INDONESIA
}

\author{
Ika Mardiansyah Putri, \\ Dinda Jusepasstina, \\ Nita Susanti ${ }^{i}$ \\ Program Study Masters Psychology Professional (PSMPP), \\ Persada Indonesia University YAI Jakarta, \\ Indonesia
}

\begin{abstract}
:
This study aims to determine the relationship between perceptions about the application of occupational safety and health with work attitudes on employees of PT. Beton Perkasa Wicaksana Jakarta. The research method used is quantitative research method, with data collection technique that is random sampling technique. The research subjects were field employees of PT. Beton Perkasa Wicaksana totaling 60 employees. Subjects were given a scale of 113 items, consisting of 51 items on the perception scale about the application of occupational safety and health and 62 items on the work attitude scale. Data were analyzed using product moment correlation and simple regression. By using SPSS 13.0 with the first result is $r$ count $(0.458)>r$ table $(0.330)$ with a significance level of $1 \%$. Both results from simple regression analysis were $0.00<0.05$. The conclusion is that there is a significant relationship between perceptions of the application of occupational safety and health with work attitudes with a contribution of $21 \%$ of perceptions about the application of occupational safety and health to work attitudes. Based on the results of the study, one suggestion that can be given is for further researchers to include other variables outside of the variables in this study such as motivation and discipline.
\end{abstract}

Keywords: perception, safety, occupational health, work attitude

\section{Introduction}

Humans need to live to work, because by working humans will get wages which will later be used to meet all their needs.

${ }^{i}$ Correspondence: email dindajuse23@gmail.com 
Along with the development of development in Indonesia, the building construction industry sector is also growing rapidly. In this regard, PT. Beton Perkasa Wicaksana is an example of a company implementing Occupational Health and Safety programs, this company is engaged in construction and industry, especially building construction, in the process with the implementation of this Occupational Health and Safety program, employees will feel safe, protected and guaranteed safety, so that it is expected to achieve efficiency both in terms of cost, time and energy and can improve the work attitude of employees, especially companies engaged in construction and industries that have a high rate of work accidents.

No exception in the field of development services. The development of physical facilities and infrastructure by both the government and the private sector opens up wide opportunities to engage in this field. Natural resources in Indonesia are abundant to be utilized in the field of construction services. In terms of employment, construction services are able to attract hundreds of thousands of workers to work on development projects.

The success and performance of one's work in a field of work is largely determined by the level of competence, professionalism and no less important, namely the attitude towards the scope of the company where the employee works. One of the keys to the success of performance improvement efforts is the positive attitude of employees towards the company. The formation of a conducive or supportive work environment will also form a good work attitude for an employee (www.library@lib.unair, 2009).

To carry out the production process in a company or organization, one of them cannot be separated from human resources where humans as labor are resources that play an important role in the organization (Siagian, 1998). In addition, changes that occur in the world of work also need to be followed by changes in attitudes, behavior and improvement of workforce skills (www.safelindo, 2009).

Work attitude is a positive or negative feeling that employees have towards their workplace or co-workers (Miner, 1992). So, the employee's work attitude towards the organization has meaning as work behavior shown by employees in working and dealing with their work environment, both the environment with coworkers and the physical work environment. A positive work attitude is indicated by a feeling of involvement, having a good attitude towards work, the need for interdependence, the nature of obedience to others, and the appearance of work.

Meanwhile, according to Azwar (1995), the formation of attitudes is influenced by several factors, namely: personal experience is what we have experienced and are currently experiencing will help shape and influence our appreciation of social stimuli.

The response to social stimuli will be one of the bases for the formation of attitudes. The influence of other people who are considered important, other people who we consider important, or have a considerable influence, be it in the community or within the family, or very special or special people will greatly affect the formation of our attitude towards something. The influence of other people and personal experiences who have never had an accident before at work and other factors so that the worker perceives 
that the implementation of the occupational safety and health program is negative which makes the employee's work attitude negative or reduces good work attitudes. In addition, the influence of culture: the culture in which we live and grow up has a considerable influence on the formation of attitudes. Our society's culture often ignores the safety factor, if they feel uncomfortable and because of a lack of awareness or participation to use equipment to protect themselves from possible accidents in the workplace. Educational Institutions and Religious Institutions: Educational Institutions and Religious Institutions as a system have an influence in the formation of attitudes. This is because they lay the foundation for understanding and moral concepts within the individual. Mass media: mass media such as television, radio, newspapers, magazines and so on which are means of information and communication, nowadays have a large enough contribution to change in society, as well as in the formation of attitudes. The influence of emotional factors: sometimes an attitude is formed in an emotion-based statement that serves as a channel of frustration or a diversion of the ego's defense mechanism. This attitude can be a temporary attitude and soon passes after the frustration is gone, but it can also be a more consistent and long-lasting attitude (Azwar, 1995).

To support the development of industrial development, it is necessary to apply modern and varied technology, the application of technology in addition to being able to benefit all production process activities in the industry can also have a negative impact on workers in the industry if it is not applied according to procedures that will have an impact on the community around the industry in the future. generally.

Work accident data in Indonesia recorded as many as 95,418 cases (in 2004), 99,023 (in 2005) and 95,624 cases (2006) decreased by 3.55 percent. These data indicate that cases of work accidents on a national scale are still relatively high (Jultiani, 2008).

The analysis of the Department of Manpower and Transmigration on cases of work accidents shows that the highest level of work accidents occurs in the construction sector. "The construction sector ranks at the top in the number of accidents or by $32 \%$, although the number of workers absorbed by this sector is relatively small, which is only 4.5 million people out of the total number of workers in all sectors which reaches 97 million," said the Minister of Manpower and Transmigration (Erman Suparno (Seputar-Indonesia, 2009).

Based on the results of the evaluation of work accident incidents so far, it can be concluded that there are several factors that cause accidents, both those that have caused fatalities and injuries, as follows: construction work accidents are caused, among others, due to the absence of construction K3 experts, the use of methods Improper implementation, weak supervision of the implementation of construction in the field, not yet fully implementing the existing provisions or regulations concerning $\mathrm{K} 3$, weak supervision of K3 implementation, inadequate both in quality and quantity of availability of personal protective equipment. Then the factor of the lack of discipline of the workers in complying with the provisions regarding $\mathrm{K} 3$ which among others, namely: the use of personal protective equipment from work accidents, is also indicated as a cause of other work accidents. 
Perceptions about the application of occupational safety and health refer to components that influence perceptions, namely experience, expectations, motivation and habits of employees to assess, interpret or interpret information (stimulus) obtained through their senses which consists of several aspects, namely: first, the work environment in it there are factors of good lighting, temperature and imperfect air circulation, noise, and working conditions. Second, machines and work tools. Third, humans themselves, human errors that often cause work accidents are unnatural attitudes, unhealthy physical conditions, and lack of skills in doing a job.

Along with the development of development in Indonesia, the building construction industry sector is also growing rapidly. In this regard, PT. Beton Perkasa Wicaksana is one example of a company that implements Occupational Health and Safety programs, this company is engaged in construction and industry, especially building construction, in the production process, where there are machines and equipment that support the process. With the implementation of this occupational safety and health program, employees will feel safe, protected and guaranteed safety, so it is hoped that they can achieve efficiency in terms of costs, time and energy and can improve employee work attitudes, especially in companies engaged in construction and industry. which has a high rate of work accidents.

There are several studies that were previously conducted by: Iverson and Buttgieg in 1988 (in Purmawati, 2005) the relationship between work safety and health climate with stress in the workplace. Depok: Faculty of Psychology UI, as quoted by Tri Agustini Prihatin (2008) states that there is a relationship between variables related to work, one of which is job security and organizational commitment. Another study conducted by Fauzi, M in 1992, the results of this study showed that the working environment has a very important role in improving work attitudes. The three studies above discuss safety and work environment issues. Within this framework, the relationship between perceptions of Occupational Safety and Health with work attitudes needs to be further tested empirically through research.

Seeing the lack of breadth of research that has been carried out and considering the importance of positive employee perceptions about occupational safety and health in relation to fostering positive work attitudes in employees, especially in the construction industry, the researchers were interested in conducting research with the title: "The Relationship of Perceptions About Implementation of Occupational Safety and Health with Occupational Health and Work Attitude of Employees of PT. Perkasa Beton Wicaksana Jakarta".

\section{Occupational Safety and Health}

Occupational safety according to Suma'mur (1989) is safety related to machines, aircraft, work tools and their processing processes, workplace foundations and their environment and ways of doing work. Work safety covers the entire process of production and distribution of both goods and services. 
Work safety according to Anoraga and Suryati (1995), the principle of applying work safety is an effort that needs to be made not only to improve an unsafe condition, but also to correct dangerous human actions (unsafe action).

Every individual wants his body condition to always be healthy in order to carry out his duties. Employees as workers also want their health to always be maintained. The essence of work safety according to Seokidjo Notiadmodjo (2003) includes two things, namely:

First, as a tool to achieve the highest degree of occupational health. The workforce here includes, among others, workers or employees, farmers, fishermen, non-formal sector workers, civil servants and so on.

Second, as a tool to increase production based on increasing productivity efficiency.

Occupational safety and health includes both terms safety risk and health risk. According to Magginson, occupational safety and health refers to conditions that are safe and secure from suffering, damage or loss in the workplace. Safety risks are aspects of the work environment that can cause fires, bruises, fractures, loss of organs, vision and hearing. They are often associated with company equipment or the physical environment and include work tasks that require maintenance and training. While occupational health refers to conditions that are free from physical, mental and emotional disturbances or pain caused by the work environment. Health risks are factors in the work environment that work beyond the specified time period, an environment that can create emotional stress or physical disturbances (Prabumangkunegara, 2005).

\section{Causes of Accidents and Employee Health Problems}

Listed below are some of the possible causes of accidents and employee health problems (Pabumangunegara, 2005):

a. Workplace Conditions

1) The preparation and storage of dangerous goods is not taken into account for its safety.

2) The workspace is too crowded and congested.

3) Improper disposal of dirt and waste.

b. Air Arrangement

1) Air change in the workspace is not good (dirty, dusty and smelly workspace).

2) Air temperature that is not conditioned by its settings.

c. Illumination Settings

1) Unable to set up and use light sources.

2) Workspace that lacks light (dim).

d. Use of Work Equipment

1) Security of worn or damaged work equipment.

2) The use of machines, electronic devices without good safety.

e. Employee's Physical and Mental Condition 
1) Damage to senses, unstable employee stamina.

2) Unstable employee emotions, fragile employee personalities, weak ways of thinking and perceptual abilities, low work motivation, clumsy employee attitudes, lack of scrutiny and lack of knowledge in the use of work facilities, especially work facilities that carry dangerous risks.

\section{Occupational Safety and Health Aspects}

Aspects of occupational safety and health according to HW Heinrich (in Anoraga and Suryati, 1995) the factors that cause work accidents are related to a person's origins and social environment that can affect attitudes and behavior in doing work, resulting in a person tending to work carelessly, not being careful and leading to the possibility of errors in work. This condition, plus other external factors such as the hazards of the work environment and mechanical equipment, results in a work accident and all its consequences. While the aspects of occupational safety and health according to Suma'mur (1996) are:

1. Work Environment

The work environment is the perception of individuals in the group about the physical conditions of the environment that can affect them in carrying out the tasks assigned to them. Unfavorable working conditions or environment for the implementation of work is an additional burden for an employee who sometimes must be borne while they carry out their work. According to Manuaba (in Tarwaka, 2004) a comfortable work environment is needed by workers to be able to work optimally and productively. Therefore, the work environment must be designed in such a way as to be conducive for workers to carry out activities in a safe and comfortable atmosphere. Factors in the work environment that are important to consider include:

a) Good lighting is lighting that allows workers to see the objects being worked on clearly, quickly and without unnecessary efforts. On the other hand, imperfect lighting, so that it is dark or can create glare, has a negative effect on work skills. Lack of light, physical deficiencies and others that exist in the company will reduce work efficiency.

b) A well-designed workspace aims to create the best possible situation at work so that the physical and mental health of the workforce can be continuously maintained and productivity efficiency and product quality can be produced optimally.

c) The ventilation system is the existence of good air circulation in the workplace, so that there is a continuous alternation of indoor air with fresh air outside.

d) Noise is unwanted sounds and can interfere with hearing and can even reduce a person's power.

e) The terms of work that are often not in accordance with the procedures such as public facilities in the company are not maintained.

2. Machinery and Work Tools. 
Every time designing equipment and work stations, human limitations must always be taken into account in addition to their abilities and abilities. Given that every human being is different from one another (Tarwaka, 2004).

3. Human

A person's ability to do work is different from someone else and is highly dependent on skills, compatibility, nutritional status, gender, age and body sizes (Suma'mur 1996). Human errors that can cause accidents, namely:

a) Unnatural attitudes and behaviors in doing work, such as employees acting recklessly, being too easy and tending to be negligent in carrying out their duties and employees tend to be lazy to use the safety equipment that has been provided by the company (Mutiara Sibarani, 2002).

b) Physical conditions and nutritional levels, especially for manual and heavy workers, are the determining factors for the degree of work productivity (Suma'mur, 1996).

c) Lack of skills in doing a job can be caused by a lack of clear direction in their duties, and a lack of understanding to carry out their duties (Mutiara Sibarani, 2002).

\section{Research Methods}

This chapter will explain the approach and research methods used in this study which include research subjects, data collection instruments, and research procedures.

In this study the method used is correlation, correlation research is research designed to determine the level of relationship between different variables in a population. The nature of critical difference is an attempt to assess the relationship and not just a description (Fox, in Seville, 1993). Measurements in this correlation are used to determine the magnitude of the direction of the relationship between one variable and another variable (Sevilla, 1993).

\subsection{Definition of Variables and Operational Variables}

\subsubsection{Variable Definition}

Research variables are everything that will be the object of research observation. Or it can also be said to be a variable with factors that play a role in the event or symptom to be studied (Fred N. Kerlinger, 2003).

Specifying a variable is a symbol to which we place a number or value. The research variable consists of two variables, namely: the independent variable or the independent variable is the perception of occupational safety and health and the dependent variable or the dependent variable is the attitude. 


\subsubsection{Variable Operation}

Operational variables contain details of the variable indicators used in the measurement. There are 2 variables in this study, namely the perception of $\mathrm{K} 3$ which is called the independent variable and work attitude is called the dependent variable.

1) Perceptions about the application of occupational safety and health referred to in this study refer to the components that influence perceptions, namely beliefs, experiences, expectations, motivations and habits to assess, interpret or interpret information (stimulus) obtained through the senses consisting of several aspects, namely: first, the work environment, in which there are factors of good lighting, spatial planning, imperfect temperature and air circulation, noise, and working conditions. Second, machines and work tools. Third, humans themselves, human errors that often cause work accidents are unnatural attitudes, unhealthy physical conditions, and lack of skills in working on a worker.

2) Work attitude is an attitude component that includes cognitive, affective, and tendencies to act as a unified system so that it cannot be separated from one another, while the work component includes interests, physical conditions, education, expectations of others, aspirations, value systems, improvement career, job security, income, working conditions, social status, social benefits that interact with each other so as to form work attitudes.

\subsection{Population and Sample}

\subsubsection{Population}

The population is defined as a group where the researcher will generalize the results of his research (Sevilla, 1993). In accordance with the problems to be studied, namely seeing "The relationship between perceptions about the application of occupational safety and health of employees of PT. Beton Perkasa Wicaksana Jakarta". Then the population is the entire field employees of PT. Wicaksana mighty concrete, totaling 200 people.

\subsubsection{Sample}

The sample is a part of the population or universe as a representative (representation) of that population (Kerlinger, 2003). Considering that the existing population is small and the willingness of the company to allow its employees to fill out questionnaires is only half of the total population, namely 100 people, the authors determine the employees in the company that will be used as research samples as many as 60 people from a total population of 100 field employees and to try out as many as 40 people.

The number of samples has met the requirements to be used as research data, this is in accordance with Guilford and Fruchter in Dede Ratna 2004), the minimum number of samples for a study is 30 people. 


\subsubsection{Sampling Technique}

Various sampling techniques are essentially ways to minimize generalization errors from the sample to the population. This can be achieved if a representative sample is obtained, namely a sample that truly reflects the population (Suryabrata, 2003).

In this study, the sampling technique used was random sampling technique. Random sampling technique is a method of selecting a sample size from a population, where each member of the population has the same opportunity and all possible combinations selected as samples have the same opportunity (Sevilla, 1993).

Where from the existing population of 200 people, 40 people were randomly selected for try out and 60 people for research.

\subsection{Data Collection Techniques}

Data collection is the recording of events or things or information or characteristics of some or all elements of the population that will support or support research (Hasan, 2002).

\subsubsection{Research Methods and Instruments}

According to Arikunto (1996), research instruments are tools used by researchers in collecting data so that the work is easier, and the results are better, in the sense of being more accurate, complete and systematic so that it is easier to process (in Hasan, 2002).

To obtain data in the study, the researcher used a scale in the form of a statement. The form of the scale used in making questions in this study is a modified Likert scale, namely by eliminating the middle answer category because it can cause the subject's tendency to answer in the middle, especially for subjects who are hesitant about the answer (Hadi, 1997).

The scale used by researchers, namely:

The perception scale about the application of occupational safety and health used in this study was adapted from the research scale of Dede Ratna Mutmainah with the title the relationship between perceptions of $\mathrm{K} 3$ and anxiety about the dangers of accidents at work for employees of PT Odira Energy Persada. The items for this scale are arranged based on the aspects contained in the notion of perceptions about the application of occupational safety and health according to Linda L. Davidoff (1988), perceptions are beliefs, experiences, expectations, motivations and habits to assess, interpret or interpret information (stimulus) obtained through the senses and Suma'mur (1985), that the perception of the application of K3 has three aspects, namely: the work environment, machines and work tools, and humans themselves. The statements compiled in the scale of the application of occupational safety and health are made with a modified Likert model scale, namely in the form of statements based on the degree of favourable. In this study, the three aspects will describe indicators of perceptions about the application of occupational safety and health. 


\subsubsection{Data Analysis Technique}

The data analysis technique used to analyze research data is in the form of statistical methods as a way to find out the relationship between variables. Determination of statistical methods must be reviewed from the type of data generated on each research variable. The variables to be analyzed are perceptions of the application of occupational safety and health as an independent variable to the work attitude variable.

The data analysis technique used to analyze research data is parametric statistics using the Pearson product moment correlation formula, this technique is used to measure how a variable is related to other variables (SPSS 13, 2004). The magnitude of a relationship (correlation) is indicated by the correlation coefficient, while the sign on the correlation coefficient shows the direction of the relationship, if the sign of the correlation coefficient is positive then the relationship is unidirectional and if the correlation coefficient is negative then the relationship is in the opposite direction.

The calculation results are obtained using the SPSS 13.0 computerized system whose results will be interpreted and correlated with the correlation coefficient table. If $r$ count is greater than $r$ table then the correlation is considered significant or in other words HA is accepted and Ho is rejected. On the other hand, if $r$ count is smaller than $r$ table then the correlation is considered insignificant or in other words $\mathrm{Ha}$ is rejected and Ho is accepted.

\subsubsection{Correlation Test}

This correlation method aims to examine the extent to which variables in one factor are related to variations in other factors. In the correlational method, the relationship between variables is studied and explained. This sought-after relationship is referred to as correlation. So, the correlational method looks for the relationship between the variables studied (Hasan, 2002).

\section{Research Result}

The research sample was 60 subjects, the perception variable about $\mathrm{K} 3$ can be seen that the average is 159.3167 , the minimum value is 127 , the maximum value is 203 , with a standard deviation value of 6.956207 . Meanwhile, the average attitude variable is 175.1667 , the minimum value is 140 , the maximum value is 248 , with a standard deviation value of 19.12507 .

\subsection{Research Score Categorization}

Categorization is done with the aim of placing respondents into categories such as low, medium, high. The perception scale on occupational safety and health and the work attitude scale are categorized into three categories, namely, low, medium and high. Where to categorize perception scores about occupational safety and health, the mean and standard deviation are needed. On the perception scale about occupational safety 
and health, the mean is 159.3167 and the standard deviation is 16.95207 . While on the work attitude scale of 19.12507.

The mean and SD were obtained from raw data obtained from the research results and processed with SPSS 13.0.

Table 1: Categorization of perception scale scores on the application of OSH

\begin{tabular}{|l|c|c|c|c|}
\hline Category & Formulation & Score Interval & Number of Respondents & Frequency \\
\hline High & $\mathrm{X} \geq \mathrm{M}+1 \mathrm{SD}$ & $\mathrm{X} \geq 176$ & 8 & $13 \%$ \\
\hline Medium & $\mathrm{M}-1 \mathrm{SD} \leq \mathrm{X}<\mathrm{M}+1 \mathrm{SD}$ & $142 \leq \mathrm{X}<176$ & 44 & $73 \%$ \\
\hline Low & $\mathrm{X}<\mathrm{M}-1 \mathrm{SD}$ & $\mathrm{X}<142$ & 8 & $13 \%$ \\
\hline Amount & & $\mathbf{6 0}$ & $\mathbf{1 0 0 \%}$ \\
\hline
\end{tabular}

Based on the table above, when the perception score about the application of K3 produced by the respondent is greater than 176, the respondent is in the high category. If the respondent's score is between 142-176, the respondent is in the medium category and if the respondent's score is below 142, then the respondent is in the low category on the perception score about the application of K3.

In addition, it can be seen that, at most PT Beton Wicaksana Jakarta employees entered the perception scale score on the application of OSH in the medium category, namely 44 subjects or $(73 \%)$ then the low category was 8 subjects $(13 \%)$ and the high category was 8 subjects ( $13 \%)$.

Table 2: Categorization of work attitude scale scores

\begin{tabular}{|l|c|c|c|c|}
\hline Category & Formulation & Score Interval & Number of Respondents & Frequency \\
\hline High & $\mathrm{X} \geq \mathrm{M}+1 \mathrm{SD}$ & $\mathrm{X} \geq 194$ & 2 & $3 \%$ \\
\hline Medium & $\mathrm{M}-1 \mathrm{SD} \leq \mathrm{X}<\mathrm{M}+1 \mathrm{SD}$ & $156 \leq \mathrm{X}<194$ & 50 & $83 \%$ \\
\hline Low & $\mathrm{X}<\mathrm{M}+1 \mathrm{SD}$ & $\mathrm{X}<156$ & 8 & $13 \%$ \\
\hline Amount & & $\mathbf{6 0}$ & $\mathbf{1 0 0 \%}$ \\
\hline
\end{tabular}

Based on the table above, when the work attitude score produced by the respondent is greater than 194, then the respondent is in the high category. If the respondent's score is between 156-194, then the respondent is in the medium category and if the respondent's score is below 156, then the respondent is in the low category on the work attitude score.

In addition, it can be seen that, at most PT Beton Wicaksana Jakarta employees were included in the medium category work attitude scale score, which was 50 subjects or $83 \%$, then the low category was 8 subjects or $13 \%$ and the high category was 2 subjects or $3 \%$.

\subsection{Hypothesis Test Results}

To answer the problems that have been stated in the formulation of the problem in the first chapter, Pearson's product moment correlation and simple regression techniques will be used. For statistical hypothesis testing assisted with SPSS 13.0, the following are the results of testing each research statistical hypothesis. 


\subsubsection{First Statistical Hypothesis Testing}

The first statistical hypothesis in this study is:

H01: there is no relationship between perceptions about the application of safety and health at work with the work attitude of employees of PT Beton Perkasa Wicaksana Jakarta.

To analyze the correlation of perceptions about the application of $\mathrm{K} 3$ with work attitudes, the product moment correlation technique with alpha $1 \%$ and $5 \%$ is used.

Meanwhile, from the results of calculations using the $r$ person product moment technique presented in the table above, it is known that the calculated $r$ value obtained is 0.458 while the $r$ table value at a significance level of $5 \%$ and $1 \%$ with N60 is 0.254 and 0.330 .

Decision: $\mathrm{HO}$ is accepted if $\mathrm{r}$ count $<\mathrm{r}$ table.

Because the calculated $r$ value $(0.458)>r$ table, both at a significance level of $5 \%$ (0.254) and $1 \%(0.330)$, the null hypothesis (Ho) states that there is no significant relationship between perceptions about the application of safety and health work with employee attitudes to work rejected. Thus, the alternative hypothesis (H1) which states that there is a significant relationship between perceptions of employee safety and health is accepted.

\subsubsection{Second Hypothesis Test Results}

The first statistical hypothesis in this study is:

H02: there is no significant contribution between perceptions about the application of occupational safety and health to the work attitude of employees of PT Beton Perkasa Wicaksa Jakarta.

To analyze the contribution of perceptions about the application of K3 to employee work attitudes, regression analysis techniques were used.

Generating R2 (0.210) shows that only $21 \%$ of work attitudes can be explained by perceptions of the application of OSH. 79\% work attitude is influenced by other variables.

From the $\mathrm{F}$ test obtained Fobserved $=15,378$ with a significance level of 0.05 . because the probability value $(0.00)$ is smaller than the alpha value $(0.05)$, this regression model can predict work attitudes. This result means that the perception of the application of $\mathrm{K} 3$ can predict work attitudes.

The formula for simple regression is $\mathrm{Y}=\mathrm{a}+\mathrm{bx}+\mathrm{e}$. So according to the formula, work attitude $=92.88+0.516 \mathrm{x}+\mathrm{e}$. where $\mathrm{x}$ is the perception. That is, without a perception of $\mathrm{K} 3$, the employee's work attitude will be $=92.88$. It should also be noted the significance of these two regression coefficients. A has a proportion of 0.00 which when compared with the proportion, the coefficient of a is significant $(0.00<0.05)$. This means that a can predict $Y$ (work attitude). B has a proportion of 0.000 which when compared with the proportion, the coefficient of $b$ is significant $(0.000<0.05)$. This means that $b$ can predict Y (work attitude). Thus, it can be concluded that every increase in the score of one perception of K3 will be followed by a work attitude of 92.884 . 


\section{Conclusion}

1) Based on the results of the data analysis conducted, the conclusions that can be drawn from this study are that there is a significant relationship between the perception variable about the application of employee safety and health with work attitudes. Thus, Ha which reads that there is a relationship between the perception of the application of occupational safety and health with employee work attitudes is accepted and Ho which reads that there is no relationship between perceptions of occupational safety and health and employee work attitudes is rejected.

2) Perceptions about the application of occupational safety and health provide a significant contribution to work attitudes. This can be seen from the results of simple regression analysis, with a significance level of 0.00 which is much smaller than 0.05. While the determinant coefficient $\mathrm{R}^{2}=0.210$ means that the effective contribution of perceptions about occupational safety and health to work attitudes is $21 \%$.

\section{Conflict of Interest Statement}

The authors declare no conflicts of interests. This statement is to certify that all Authors have seen and approved the manuscript being submitted. We warrant that the article is the Author's original work. We warrant that the article has not received prior publication and is not under consideration for publication elsewhere. On behalf of all Co-Authors, the corresponding Author shall bear full responsibility for the submission. This research has not been submitted for publication nor has it been published in whole or in part elsewhere. We attest the fact that all Authors listed om the title page have contributed significantly to the work, have read the manuscript, attest to the validity and legitimacy of the data and its interpretation, and agree to its submission to the European Journal of Human Resources Management Studies.

\section{References}

Anoraga, P. and Ninik, W. (1993). Psychology Within the Company. Jakarta: Rineka Cipta. Azwar, S. (1995). Human Attitude, Theory, and Its Measurement. Yogyakarta: Student Library.

Davidoff, L. Linda. (1988). Introduction to Psychology. Jakarta: Erlangga.

Hasan, M. I. (2002). Main Materials of Research Methodology and Its Applications. Jakarta: Ghalia Indonesia.

Kerlinger, F. N. (2004). Principles of Behavioral Research. Yogyakarta: Gajah Mada University Press.

Prabumangkunegara, A. (2005). Company Human Resources Management. Bandung: Rosdakarya Youth.

Seville, et al. (1993). Introduction to Research Methods (translation). Jakarta: UI-Press. 
Suryabrata, S. (2003). Research Methodology. Jakarta: PT. Raja Grafindo Persada.

Tarwaka (2004). Ergonomics for Occupational Safety, Health and Productivity, Ed.1. cet.1. Surakarta: UNISBA Press. applied to their work. Under the terms of this license, no permission is required from the author(s) or publisher for members of the community to copy, distribute, transmit or adapt the article content, providing a proper, prominent and unambiguous attribution to the authors in a manner that makes clear that the materials are being reused under permission of a Creative Commons License. Views, opinions and conclusions expressed in this research article are views, opinions and conclusions of the author(s).Open Access Publishing Group and European Journal of Management and Marketing Studies shall not be responsible or answerable for any loss, damage or liability caused in relation to/arising out of conflict of interests, copyright violations and inappropriate or inaccurate use of any kind content related or integrated on the research work. All the published works are meeting the Open Access Publishing requirements and can be freely accessed, shared, modified, distributed and used in educational, commercial and non-commercial purposes under a Creative Commons Attribution 4.0 International License (CC BY 4.0). 